This item was submitted to Loughborough's Research Repository by the author.

Items in Figshare are protected by copyright, with all rights reserved, unless otherwise indicated.

\title{
An examination of the copyright clearance activities in UK Higher Education
}

PLEASE CITE THE PUBLISHED VERSION

PUBLISHER

Sage Publications Ltd / @ Elizabeth Gadd

VERSION

AM (Accepted Manuscript)

LICENCE

CC BY-NC-ND 4.0

REPOSITORY RECORD

Gadd, Elizabeth A.. 2019. "An Examination of the Copyright Clearance Activities in UK Higher Education". figshare. https://hdl.handle.net/2134/4303. 
This item was submitted to Loughborough's Institutional Repository (https://dspace.lboro.ac.uk/) by the author and is made available under the following Creative Commons Licence conditions.

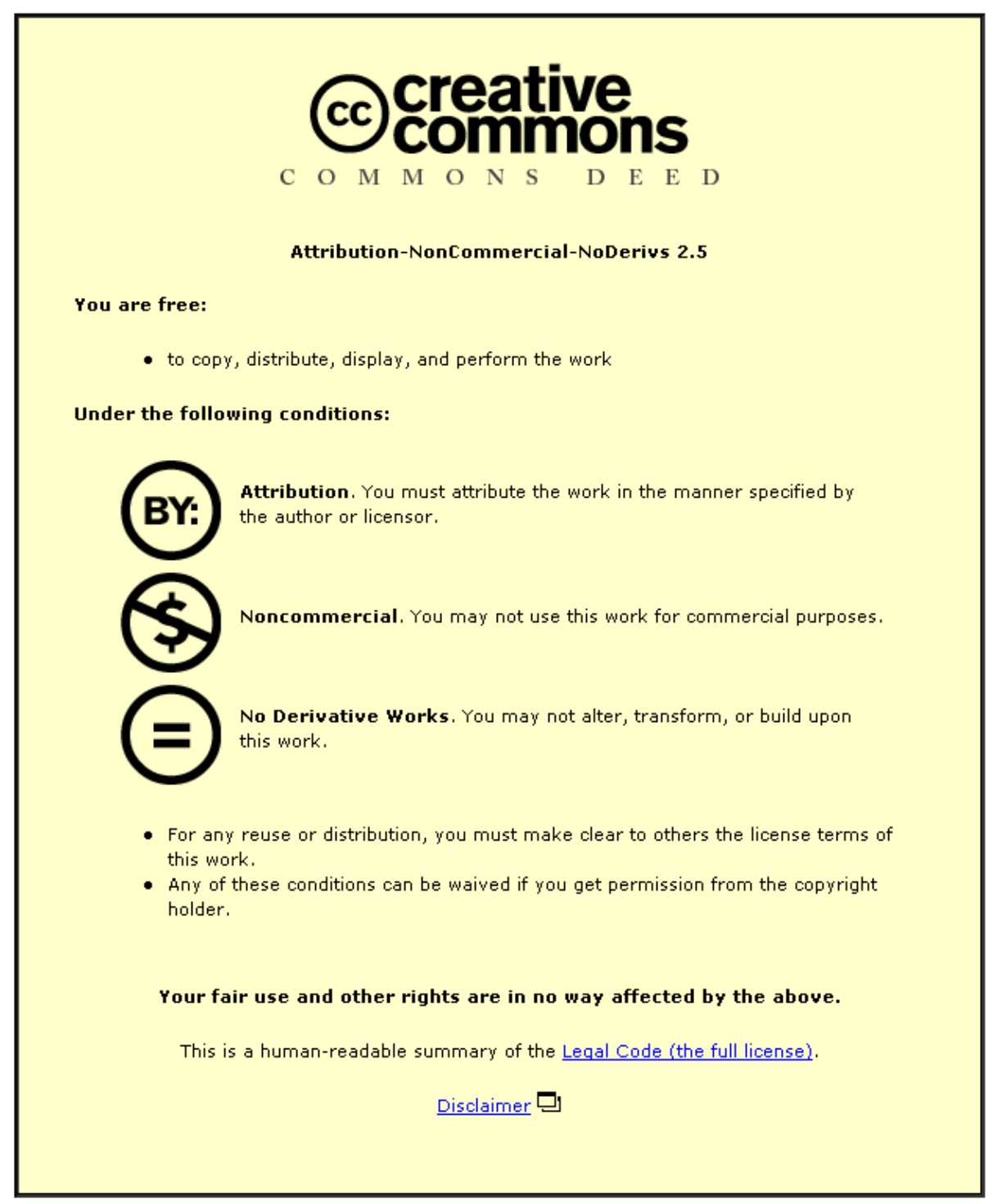

For the full text of this licence, please go to: http://creativecommons.org/licenses/by-nc-nd/2.5/ 
Title: An examination of the copyright clearance activities in UK Higher Education

Author: Elizabeth Gadd, Loughborough University

Contact details: $\quad$ Pilkington Library

Loughborough University

Loughborough

LE11 3TU, UK.

Tel: 01509222369

Fax: 01509223993

Email: e.a.gadd@lboro.ac.uk

Biographical note:

Elizabeth Gadd is currently an Academic Librarian at Loughborough University. She also worked on the eLib project ACORN. She holds an MSc in Information Studies from Loughborough University. Her research interests centre on the management of copyright in the delivery of information services, with a particular focus on electronic services. She was the winner of the 2000 Elsevier/LIRG Research Award.
Abstract:
Reports results of a questionnaire survey of 57 persons with copyright clearance functions in UK Higher Education Libraries and beyond. research project supported by the 2000 Elsevier/LIRG Research Award, entitled "Clearing the Way: copyright clearance in UK Libraries". Examines the questionnaire responses and case study interviews with regard to the copyright clearance process. Provides an overview of clearance in UK HEIs, namely: who clears rights and where; what materials were being cleared and for what purpose; and what licences and clearing houses were used. It then examines the clearance procedures themselves: receiving requests from internal customers, tracing rights holders, sending requests, rights holder response times and chasing, refusals and unanswered requests, and the terms of permission, including cost. Concludes that copyright clearance is a complex, time-consuming activity for libraries, and that the problems could be addressed on many levels. 
When Higher Education (HE) libraries wish to make copies - print or electronic - of copyright materials which go beyond what is allowable under copyright law or the various copyright licences, they have to seek permission. This has always been the case. However, recent years have seen an increase in this activity in response to a number of factors. The problem of large student groups, whose needs cannot be met by traditional library provision, is often solved by the provision of coursepacks or electronic "short loan" collections. Distance learning students are also often provided with packs of information either in print or via the internet. On-campus students are also benefiting from more educational technology such as computer-aided learning packages, and electronic learning environments. To include copyright materials in all these services requires copyright clearance.

Such is the demand for clearance that more organisations are dedicating human resources to deal with it. A recent issue of the Library Association's “Appointments” publication advertised no less than three posts that involved copyright clearance duties. One University revealed that their clearance figures have increased three-fold in the last six years. The email discussion list, Lis-Copyseek, set up for the discussion of copyright clearance issues amongst librarians, has recently reached a record 189 members.

Against this backdrop, and the forthcoming European Union Copyright Directive (CEC, 1999) and re-negotiation of the Copyright Licensing Agency (CLA) HE Licence, it was felt that an investigation of the clearance processes faced by libraries would be timely. The intention was that some recommendations on library-friendly legislation and licensing, and some best-practice guidelines for copyright clearers, would result. The research was supported by the 2000 Elsevier/LIRG Research Award and took a two-pronged approach: firstly a questionnaire to copyright clearers, and secondly a series of five case study interviews. It was recognised that clearance is not the sole domain of libraries, therefore anyone who cleared rights was encouraged to complete the questionnaire that was mounted on the web and advertised by email.

This article reports on the results of the questionnaire survey and case study interviews with regard to the copyright clearance process. It firstly provides an overview of clearance in UK HEIs, namely: who clears rights and where; what materials were being cleared and for what purpose; and what licences and clearing houses were used. It then examines the clearance procedures themselves: receiving requests from internal customers, tracing rights holders, sending requests, rights holder response times and chasing, refusals and unanswered requests, and the terms of permission, including cost.

\section{Responses}

Fifty-seven questionnaire responses were received. Fifty-one (89\%) of the respondents classed their organisation as a Higher Education Institution (HEI). The other six respondents were from Further Education (FE) colleges, Public Libraries or specific projects requiring clearance. The $51 \mathrm{HE}$ respondents represent $30 \%$ of the total 169 HEIs (HESA, 1999). However, as the respondents were a self-selecting sample, it would be inaccurate to infer any statistical significance from the results. 


\section{Where the clearance takes place}

It was not assumed that respondents would all be based in libraries, so the question was posed: "Where does the majority of your organisation's copyright clearance activities take place?”. There were 56 responses to this question. In total 55\% (29) of respondents stated that copyright clearance took place in the Library. Nineteen (37\%) of these said the clearance was done by library staff. The other ten (18\%) by dedicated copyright staff/units. The remaining $45 \%$ indicated that copyright clearance was undertaken elsewhere in the organisation. Twenty respondents (35\%) stated that this was done by individuals such as academic, administrative, or project staff, and five (9\%) by dedicated copyright units elsewhere in the organisation.

\section{Figure 1}

Although these responses gave an indication as to where the majority of clearance was undertaken, seven respondents (13\%) commented that responsibility for clearance was shared with other parts of the organisation. One HE respondent stated that clearance was done both "in the Library by Library staff and by University Departmental Staff for Departmental material”. This was a common occurrence, as someone else concurred "Library staff clear material for stock (i.e. offprint collection) but academic depts clear for study packs."

These data suggest that libraries are still the main focus for copyright clearance within HEIs, despite the range of alternative clearance centres in use. Weedon's (2000) recent research into IPR policies in Higher Education Institutions supports this view of the library as an important source of copyright knowledge.

\section{Who takes on clearance}

There were 52 responses to the question, "As far as you know, how many people in your organisation clear rights?" and the request to give their job titles, and the proportion of their time they spend clearing rights. However five of these responses were comments suggesting this was "impossible to answer" due to the large number clearing rights in various parts of the organisation. Another raised the point that more and more staff are taking on many different roles and therefore often have multiple job titles.

\section{Number of clearance staff}

There were forty-three responses from which the number of clearance personnel could be measured. For analysis purposes a figure of $>1$ was entered where the respondent hadn't given a number but where it was clear there were multiple clearance staff. The " $>4$ " was entered on the basis of the job titles specified. The responses are given in Figure 2.

\section{Figure 2}

Sixteen respondents (37\%) thought that they were the only one in their organisation that cleared rights. The remaining $63 \%$ of organisations committed at least two members of staff to this activity. Indeed three organisations had five staff clearing rights, and two had 24 rights clearers. This latter category included an organisation 
that offers courses by part-time and distance learning, and an organisation that has one rights clearer for each of its 24 schools.

\section{Time spent on rights clearance}

Perhaps a more significant measure of the staff intensity of rights clearance is not the number of staff clearing rights, but the time they spend doing it. For example, there may be two staff clearing rights, but if they each just spend five hours a week on it, this amounts to just under one-third of a FTE staff member. The data was therefore analysed by converting responses into percentages of a staff member's time, using an average 35-hour week, and a 20-day month.

Thirty-nine respondents (68\%) estimated the amount of time they and their colleagues spent on rights clearance. The responses are illustrated in Figure 3.

\section{Figure 3}

Figure 3 plots the percentage of a full time staff member required for clearance, against the number of respondents citing that figure for their organisation. The median amount of time spent clearing rights is $15 \%$ or five and three-quarter hours (almost a day) a week over the year. The mean number of hours per week (excluding the HEI that had 24 full-time clearers) is $30 \%$ or ten and a quarter hours (a day and a half) per week over the year. However, as many respondents commented, clearance work is very seasonal. "The time spent depends on the time of year" said one respondent, "Late August, September, December and January I could be spending at least the equivalent of a working day a week clearing rights if you count advising tutors and ringing CLARCS [Copyright Licensing Agency Rapid Clearance Service] with alterations to the original lists." Also, where the respondent knew there were a large number of clearers at their organisation, they often only counted the clearance done by their department, or made no estimate at all. This may have made the resulting figure artificially low.

\section{Job titles of staff clearing rights}

Thirteen different job titles were specified as those with clearance responsibilities. The list, together with the number of times they appeared in responses, given in Table 1 .

\section{Table 1}

The most frequently mentioned group were dedicated copyright personnel, although this figure was perhaps artificially inflated by the team of 24 dedicated copyright clearers at one institution. Disregarding this 24, there remained eight clearers with job titles such as Copyright and Licensing Officer, Copyright Librarian and Copyright Assistant. Interestingly, Subject Librarians and Library Assistants occurred equally frequently, and Administrative Assistants were cited as copyright clearers in eight organisations.

Perhaps the dominant characteristic of the list was the sheer range of personnel that took on a clearance role. Indeed, in very few HEI's was the clearance staffing the same. This is not necessarily an indicator that the approach to copyright clearance in $\mathrm{HE}$ is haphazard or unplanned, but there does seem to be confusion as to the status of 
copyright clearance. Is it an administrative role, a library professional's role, a technical role, or a managerial role? The answer partly depends on what types of materials are being cleared, for what purpose and in what way. However, while an efficient administrator may handle routine text clearances, copyright clearance is never entirely routine. Where there is a clearance service there will always be the need for some professional or managerial oversight to deal with the inevitable and difficult interpretation of copyright law and licences.

\section{What rights are being cleared?}

Respondents were asked to select from a list the purposes for which they were clearing copyright. There were 13 options including an "other" category. Fifty-three responded to this question. Figure 4 shows the number of services or purposes for which respondents were clearing rights.

\section{Figure 4}

It can be seen that the majority of respondents (60\%) clear rights for only one or two services. Just under 30\% needed to clear rights for three or four services, and $10 \%$ had over five services for which they undertook clearance. Comments from respondents indicated that the number of services demanding clearance was on the increase. "People will want to use copyright material in more and more different ways" said one. Figure 5 illustrates the different types of service or purpose for which the respondents cleared rights.

\section{Figure 5}

The purpose for which the largest proportion of respondents cleared rights was the creation of coursepacks. Indeed 55\% of respondents (29) undertook this activity. As coursepacks are not usually cleared for library collections but for classes of students, further analysis was performed to see whether it was the library-based clearers who were undertaking the clearance. For 16 of the 29 organisations (55\%) coursepack clearance was done in the library, leaving 13 institutions (45\%) where coursepacks were cleared elsewhere. This ratio correlates exactly with the overall numbers of copyright clearers within and without libraries as stated above.

Following closely behind coursepack clearance was clearance for Short Loan Collections with $47 \%$ of respondents undertaking this activity. Only one respondent mentioned clearance for other library collections.

Clearance for distance learning activities was very common. Overall 20 (38\%) respondents indicated that they cleared rights for distance learning course materials of some kind. Interestingly printed distance learning materials were the most popular. They were cleared by $25 \%$ of respondents. Distance learning materials for web delivery were cleared by $21 \%$ of respondents and for CD-ROM delivery by $9 \%$. Electronic Short Loan Collections were cited by nine respondents (17\%) as a service requiring clearance, and Electronic Learning Environments by seven respondents (13\%). Other electronic developments such as computer aided learning packages and digitisation projects were mentioned by a small number of respondents, as was clearance for individual staff members' own publications. 
Twenty-one respondents (40\%) said they cleared rights for purposes other than those listed. These included theatrical productions, slide collections, clearance of individual pages for journal binding, "Village packs of historical material", TV, AV and video, exam paper collections, software and film footage. One large clearance unit cited a long list of additional clearance activities thus: “TV, Video, Audio, Collaborative packages, University publications, actors, film footage, scripts, sound recordings, presenters, musicians etc.”

Perhaps the most striking finding was that there were at least 28 different activities within Higher Education that required clearance. This is a considerable number, particularly as each different activity requires a different type of approach to rights holders, and a new set of terms and conditions. It seems likely that the number is larger now than it has ever been because of the fairly recent introduction of electronic services and certain teaching and learning developments (Distance Learning, CAL, etc.). Indeed one interview candidate suggested that moves in libraries from a "holdings" to an "access" culture makes the current environment perfect for the establishment of centralised in-house clearance services.

\section{Which materials are being cleared?}

It was not only the range of services requiring clearance that was broad, but also the range of materials being cleared for those services. Respondents were asked to list the types of material for which they were clearing rights. Thirteen options were given including an "other" category. Figure 6 illustrates the responses to this question.

\section{Figure 6}

Ninety-four per cent of respondents said that they cleared book chapters and/or journal articles. Less than half this figure (42\%) cleared the next most popular category of materials: newspaper articles. Variety was the dominant characteristic with twelve different categories of material requiring clearance.

Some respondents reported difficulties clearing book chapters due to publisher concerns that clearance income would replace book sales. For example, some publishers have limited the volume of book clearance they will allow through CLARCS in terms of the number of pages from one text, or the total number of coursepacks allowed. This is disappointing because it is the large groups of students whose needs are not met by traditional library provision that benefit the most from coursepacks of chapters and articles. It is the view of some clearers that publishers marketing books on a chapter-by-chapter basis could solve the problem. While many publishers are concerned that this is not a viable economic model, others are testing it (Guernsey, 2000).

\section{Licences}

Having ascertained what materials were being cleared and for what purpose, the next step was to determine how the clearance was done. One of the provisions of the UK Copyright Designs and Patents Act of 1988 (CDPA88) was for the establishment of licensing organisations by rights holders. These organisations would licence to user communities the right to make additional copies over and above those allowed by law. 
Income from such licence fees would then be distributed amongst the represented rights holders.

Respondents were asked to select which copyright licences they took out from a given list. Fifty-four organisations responded.

\section{Figure 7}

Thirty-seven percent of respondents indicated that they took "other" licences. These are listed in Table 2.

\section{Table 2}

In total fourteen different types of licence were handled by respondents. It is unlikely that every copyright clearer has to come to a working understanding of this many licences. However it does give an indication of the scale of the licensing issue bearing in mind that copyright licences are not always the easiest to interpret, and that many clearers are administrative or paraprofessional as well as part-time.

One of the main complaints from respondents was that licences were becoming more and more restrictive, offering users less for their money, and necessitating additional clearances. This is a significant issue as the intention of the provision made in the CDPA88 for licensing organisations was surely to save users from extra burdensome clearances. It seems that users have found themselves with up to fourteen additional licences, and a large clearance bill. One interviewee disclosed that their CLA HE Licence fee in 1999 amounted to $£ 71,700$ while their CLARCS clearances for the same year cost a further $£ 34,500$ - an additional $50 \%$ on top of the licence fee.

One of the ways that Licensors could assist clearers therefore is to reconsider what clearances they allow under a flat-fee licence, to reduce the volume of additional clearances required.

\section{Clearing houses used}

As previously mentioned, copies not permissible under law or licence have to be cleared individually with rights holders. To alleviate some of the burden for copyright clearers, and to save rights holders being inundated with requests, a small number of clearing houses have been established. Respondents were asked to indicate which clearing houses they used and what their experiences of them were. Three such services were listed: CLARCS (print) CLARCS (digitisation), and HERON (Higher Education Resources ON-demand). Forty-four of the 57 respondents (77\%) indicated that they used some form of clearing house. That left a large proportion - almost onequarter (23\%) - that didn't rely on clearing houses at all. Figure 8 shows the services used.

\section{Figure 8}

Corresponding with the large number of respondents clearing printed coursepacks CLARCS was the most frequently cited clearing house. Interestingly the new Digitisation clearing house was fairly well used too. The pilot HERON service was in use by one-quarter of the clearing house-using respondents. Of the "other" responses, 
six mentioned the British Library Copyright-Cleared Copy Service. This was omitted from the services listed as options because the primary focus of the service is document delivery. However, many organisations use the copyright-cleared facility and in retrospect it would have been useful to have included it on the list. The US Copyright Clearance Center (CCC) was cited by two respondents as a service they use.

\section{Experiences of clearing houses - CLARCS}

Thirty-five respondents commented on their experience of the CLARCS service. Responses were analysed and categorised as positive, mixed or negative, to get an overview of the community's experience.

\section{Figure 9}

Opinion is clearly split about CLARCS. The positive comments included two that rated CLARCS as either "excellent" or "very good". Eight were broadly positive with comments such as "In general good", "OK on the whole", and "Quite good, some non-replies". Two praised the speed of the service as "quick" while three applauded the staff with comments such as "staff very courteous and helpful even when under duress”. Another wrote:

CLARCS is a very good service, especially the web-based database for initial checking of clearance prices. I have had very positive experiences dealing with the CLARCS operators; they are efficient and tend to respond very quickly to enquiries (same day for phone calls and within 2 days for faxed queries).

The "mixed" responses consisted of those that found the service changeable, and those that saw a good and a bad side to the service. In the first category there were comments like: "Recently been a bit slow, but generally good", "Previously bad but have since improved slightly", and "It varies. Sometimes good, at other times not so." In the second category comments were of the "good but..." variety, with complaints about "the high costs for study packs", CLARCS not giving "advice" or giving poor advice, "offhand" staff and "problems getting through to CLARCS and ...long delays in receiving quotes."

The negative comments were strongly worded using verbs such as "appalling", "dreadful" and "terrible". Many complained about "a very poor level of customer service". One person described it as "bureaucratic, old fashioned, not designed with users needs in mind [and] wasteful of resources", another as "very slow and cumbersome". One respondent found the CLA a prohibitive intermediary between library and publisher:

"[CLARCS is] inadequate for my needs, quite often the CLA is unable to clear the quantity I require or clear for electronic use. So time is often wasted going between the CLA and the publisher. The publisher doesn't want to know and the CLA can not move without the publisher amending their original contract!”

There were also complaints of an "unhelpful attitude”, amongst staff. One respondent wrote: 
"their staff do not always know what they are doing and they have a "the customer is always wrong" attitude."

Another wrote, "the 'front desk' of CLA is intellectually not up to the job”.

The length of time taken for clearance was bemoaned by a number of respondents with comments such as "slow to respond to emails", "poor response time - takes several days", and "takes weeks in busy periods". One respondent pinpointed specific delay problems with the introduction of new licence clauses.

It is clear that CLARCS would benefit from some service adjustments. Additional staff at peak times of the year (particularly over the summer) and after any changes to the Licence would alleviate any bottlenecks. Customer service training for some staff may also prove beneficial. In practical terms, a "sale or return” scheme for coursepacks that are cleared and then not sold would be welcomed, as would a simple way of ordering repeat coursepacks. The disparity of opinion over the CLARCS service may be the result of differing expectations. These might be overcome should the CLA expand upon recent moves towards user consultation, perhaps performing a thorough CLARCS user survey. Another option might be the establishment of a CLARCS “customer charter”. This would both provide clarity over the level of service customers should expect, and allow CLARCS to chart their service level against set goals and criteria.

\section{Experiences of clearing houses - HERON}

HERON is an eLib project that has been funded by JISC and Blackwell Retail Ltd over a period of three years on a reducing basis.

The aims of HERON are to:

- develop a national database and resource bank of electronic texts which will widen access to course materials and improve the quality of learning throughout Higher Education in the UK;

- co-operate with rights holders and representative bodies to remove blockages in copyright clearance and to determine appropriate fee levels and conditions for the digital age;

- provide a one stop shop for copyright clearance and digitisation for UK Higher Education Institutions (HEIs).

In undertaking this role, HERON aims to reduce duplication of effort in digitisation and remove the burden of copyright clearance from individual HEIs. At the same time it hopes to reduce problems for publishers that might otherwise find themselves being deluged with requests from multiple sources. HERON are working with the CLA's Digitisation Service for some clearances, while negotiating others on their own.

There were just four comments relating to the HERON service. One stated that "HERON is developing nicely". Another wrote that "HERON promise a lot, but so far we haven't had any delivery for various reasons and we have little faith in their 
ability to meet our needs.” One HERON-user cited the difficulties of copyright clearance generally as the main hindrance to the new service. The final comment concerning payment - was from a respondent who stated that they would "mostly" use "HERON but will also use the CLA for the big British publishers, as they don't charge $10 \%$ on top of the clearance fee."

\section{Benefits}

The unique characteristic of HERON is that it will attempt to clear any printed materials on your behalf, unlike the British Library and the CLA that are only able to clear materials from rights holders that have mandated them. HE certainly seems to have caught on to the fact that HERON offers a convenient, value-added, interface to the CLA's Digitisation service, as the recent CLA newsletter notes: "Most licensed HE institutions have chosen to manage their digitisations through the JISC-funded HERON project" (CLA, 2000). Because the service is based in the HE sector and is not employed by rights holders it should avoid some of the difficulties that CLARCS has faced.

HERON may also give HE “a stronger negotiating position to lower fees” as one respondent hoped, and there may be other economic benefits. One interviewee pointed out that the current subscription price to HERON of $£ 800$ is cheaper than a member of staff would cost to do the clearances. Also, if HERON are unable to get clearance and/or provide a digital file of the material you need, within the timescale you specify, no fee is payable. It therefore offers a no-risk option for cash-strapped HEIs embarking on digitisation projects.

\section{Disadvantages}

There are a number of difficulties HERON has to face however. Firstly the long-term viability of a resource bank seems to rest on the assumption that there is overlap amongst HEIs as to what they want cleared and digitised. Initial work by some of the On-Demand Publishing and Electronic Reserve eLib projects cast doubt whether this was the case (ACORN, 1998).

Secondly, although HERON is working closely with the CLA to obtain clearance for materials from publishers that mandate the CLA, there are many requests that cannot be cleared through this route. For example, overseas publishers and many smaller rights holders need to be approached individually. Typically such rights holders are the more difficult part of the marketplace: smaller publishers can be hard to locate, and overseas publishers can be hard to contact and communicate with. Direct negotiations with any rights holder is time consuming, but even more so when negotiating electronic rights, until publishers begin to develop their own policies on electronic permissions.

Thirdly, in addition to the subscription fee, HERON adds an administration fee to each successful transaction. This is done as part of HERON's move towards becoming self-supporting, but may make HERON's costs appear high to institutions.

Many of these problems will be teething problems. Once the service is up and running and they have agreements with a good proportion of the rights holders, the process should speed up and prove more and more valuable to HE. 


\section{The clearance process}

Having asked the "who, what, where and why" of copyright clearance, the only remaining question is "how". How is copyright clearance done? How long does it take and how much does it cost?" The remainder of this article will be spent answering these questions. A map of the copyright clearance process as described by respondents and interviewees is given in Figure 10. The length of the procedure is immediately obvious, and one of the overarching complaints was the amount of paperwork it generates, necessitating meticulous administration skills. Such skills are particularly important because the terms of permission constitute a legal contract and a clearer may be asked at any time to produce evidence of their permission to reproduce that intellectual property.

\section{Figure 10}

\section{Receiving requests from internal customers}

One thing the research made very clear was that copyright clearers occupy an uncomfortable middle ground between their users and the copyright legislators and licensors. As professionals they are eager to ensure that intellectual property is respected and used only with appropriate permission. As service providers they are keen to make intellectual property as accessible as possible, and to remove all barriers to its use. However, the copyright legislation that intends to protect intellectual property from misuse also creates huge barriers to its use. In educating their users about that copyright legislation, their users often accuse copyright clearers of pedantry and bureaucracy as though they had created the laws themselves. And in lobbying legislators and licensors for clarification on the copyright situation, and for fair educational use of intellectual property, copyright clearers are often suspected of abusing the copyright system.

We see this factor at work both in the relationship between clearers and rights holders above, and also in the relationship between clearers and their internal customer base. One respondent wrote: "the library is often seen as 'being awkward' by our academic colleagues because we have to implement these [copyright] regulations." Another wrote

"Students and lecturers get frustrated and I feel like a bureaucrat which is not why I chose a career in librarianship. (I had one instance where a law lecturer here had written an article (about music copyright) and wanted it to go into the short loan the publisher refused permission and I had to tell him he couldn't put his own article into the collection! Ridiculous!)”

In practical terms, one of the main difficulties clearers face is getting adequate bibliographic information from internal customers in an appropriate timescale in order to process their requests. One respondent put this succinctly:

"Requests from internal customers, Problems: 1. Insufficient bibliographic information. 2. Unrealistic time-scales (e.g. academic staff as requestors don't leave enough time for the clearance process.)” 
Another reported: "[Its] a constant problem to make academics appreciate the possible delays in getting clearance", which results in "internal customers [that] never allow sufficient time to obtain permission”.

Designing a clearance request form is one method clearers use to ensure they have all that information (assuming it's filled in correctly). This also puts some of the onus back on the customers during busy periods.

\section{Checking requests}

All the interviewees checked the bibliographic references of all the requests they received. This was a massive, but - they felt - unavoidable, task. They then checked to see whether the materials actually required clearance by considering whether the copying fell within the fair dealing or insubstantial use exceptions of the CDPA88. Interestingly, those interviewed found it too time-consuming to check whether requests are covered by electronic full-text sources purchased by the institution. This probably means that some clearance requests are being made unnecessarily. However, some research done by Calvert (2000) into the impact of full-text databases on inter-library loans (ILL) revealed that only a very small percentage of ILL requests were available on such databases, and that it was not cost effective to check them prior to submitting ILL requests. It seems likely that the same would apply to clearance requests. A final double check done by interviewees was to see whether the items requested were authored by someone in the organisation. This information helps in the negotiation of lower (or no) fees.

\section{Tracing rights holders}

Having checked the requests, the next step was to trace the rights holders in those works (unless the request was first sent to a central clearing house). Tracing rights holders - particularly small publishers, overseas publishers, or individual authors/creators - is notoriously difficult. As one respondent wrote, "it can be very hard to trace small publishers and imprints that have been swallowed up by big multinational publishers.” Once the publisher has been ascertained, Gadd (1997) noted that "there is also no standard member of staff who deals with...copyright permissions: it may be the Journals Manager, the Rights and Permissions Department, the Electronic Publishing Manager, the Editor, or a number of others”. Of course, these problems proliferate when trying to locate individual authors or creators who are often not represented by any larger body.

\section{Sending requests}

Once the rights holder has been located, the request can be sent. Twenty-nine respondents estimated the number of items they cleared per annum. Three respondents gave their answer in terms of coursepacks produced, namely, less than ten, 22 and 100 per annum. The other responses are tabulated below.

\section{Table 3}

Excluding the large number of items cleared by one dedicated copyright unit with 24 full time staff (7,000-8,000 p.a.), the median number of items cleared per annum was 300 and the mean number was 439. However, the largest group of respondents cleared under 100 items per annum. Two institutions only cleared 2-3 items a year. Of the nine organisations that cleared over 500 items a year, eight did so using staff 
based in the library. Five of these had dedicated copyright staff based in the library and three used regular library staff who dealt with clearance alongside their other duties. The other organisation had a dedicated copyright officer based outside the library.

All interviewees used a pro forma permission request letter to send to rights holders. Some also found an accompanying standard response form a useful addition. Such forms may speed up the process if the rights holder is small and hasn't got it's own systems in place. Also, by specifying exactly the rights required on such a form, it reduces the risk of misunderstanding and therefore future negotiations.

\section{Rights holder responses}

Respondents were asked how long it takes, on average, for permission to come through, and to specify according to different types of material and purpose where possible. Thirty-six responded to the question. Twenty gave a figure without specifying the type of material or purpose to which it applied and these responses are illustrated in the graph below. The other sixteen responses are tabulated in Table 4.

\section{Figure 11}

Two weeks was the median length of time taken to gain permission, although the mean (and mode) was one month. However, waiting for two or three months was not uncommon, and for some the average waiting time was over three months. Those respondents that specified the length of time taken for a variety of clearance purposes shed more light on this. (Please note that the number of respondents does not add up to 16 as respondents gave different estimates for different clearance activities.)

\section{Table 4}

Many respondents drew the distinction between the time taken for clearance if CLARCS had a mandate compared to the time taken if they don't. Responses such as "CLARCS 1-2 weeks, Direct 4-8 weeks" were fairly common. Another respondent compared the response time from UK and US publishers thus: "Direct from UK publishers - 2 weeks, Direct from US publishers - 2-3 months". Some found that obtaining permission for electronic copies took longer because of publisher uncertainties as to a) whether they own the electronic rights; b) what to charge; and c) what security measures to impose. The author requested permission to create electronic copies of three journal articles from a well-known American publisher in October 1996 and received no response for four years - until July 2000 when the permission was finally granted.

Interviewees reported that because of the time it takes for permission to come through they have to impose a lead-in time of anything up to six months on their internal customers (a rule that is often flouted). The difficulties associated with applying directly to rights holders for permission highlight the value of established clearing houses. 


\section{Chasing permissions}

With rights holder responses taking weeks if not months, chasing requests becomes a necessary part of the clearance process. Respondents were asked to give the percentage of permissions they had to chase before receiving a response. Twentynine responded to this question, three of which said they didn't have to chase any responses. The remaining $90 \%$ of respondents had to chase. The responses are given in the figure below.

\section{Figure 12}

The largest group of respondents (8) chased between one and ten per cent of their permissions. The remaining responses were spread right across the spectrum with two saying they had to chase all or virtually all of their permission requests for a response. The mean percentage of items requiring chasing was $35 \%$. The median figure was $30 \%$.

Eighteen respondents gave both the approximate number of items they cleared per annum, and the percentage of items requiring chasing per annum. This allowed the calculation of a mean number of items chased per annum. Excluding the unusually high number of items chased by the large dedicated Copyright Unit $(4,200)$, the average number of items chased per HEI came to 97. The median number of items chased per annum was 40 .

Respondents were also asked how many times they would chase an item before giving up. Twenty-four respondents answered this question. Two stated they would "keep going as long as the person asking for the copy is willing to wait”. Another said they would "never give up!”. The responses of the remaining 21 are given below.

\section{Figure 13}

Most respondents said they would chase more than once - and four stated that they would chase up to five or six times. The median number of chases performed was two.

Fifteen respondents gave the approximate number of items they cleared per annum, the percentage of items requiring chasing per annum, as well as the average number of chases they gave to an item per annum. This allowed the calculation of a mean number of chases per annum. Again, excluding the unusually high number of chases performed by the large dedicated Copyright Unit, the average number of chases per annum was 315. That's a lot of additional administration on top of an already paperintensive and time-consuming process.

\section{Refusals}

The issue of refused requests wasn't covered by the questionnaire. However some data on the proportion of refusals was received from one interview candidate and from HERON. Of the 706 requests that HERON had received a response to in March 2000, 66 of them (9\%) were refused. In just over three years, one institution had received responses to 792 requests of which only 21 (1\%) were refusals. However, there were an additional 75 requests that received no reply. 


\section{Requests never answered}

The issue of unanswered requests was dealt with by the questionnaire, which asked how many requests were never answered at all. Twenty-three responded. Two stated that they always receive a response. Five said that very few requests were never answered. One wrote "Publishers are hopeless if we have to go direct to them...most never respond but as part of the total clearance process this is a very small [percentage]". Others concurred that it was the direct applications to publishers that were more likely to receive no response. Another elaborated that it was "mainly overseas publishers" that fell into this category. The remaining respondents gave a percentage of their total requests that never receive a response. The results are given in the graph below.

\section{Figure 14}

Fifty-six per cent of those answering this question said that between one and ten per cent of their requests were never answered. A smaller proportion said the figure was between 11 and 20 per cent. The mean proportion of requests never answered was $12.5 \%$, while the median was $5 \%$.

Thirteen respondents gave both the approximate number of items they cleared per annum, and the percentage of requests that were never answered. From these figures, the mean number of requests that were never answered came to 25 , while the median figure was higher at 40 .

It is impossible to interpret a lack of response, however the legal interpretation is as a refusal - i.e. one cannot go ahead and copy without explicit permission. At a recent seminar attended by the author, one delegate made the point that only those who are prepared to make use of rights should own them. It would certainly be most helpful to clearers if this were the case.

\section{Terms of permission}

Even if a request has been successful and permission has been granted, a copyright clearer's work is still not over. This is because permissions are often granted under certain terms and conditions specified in the Rights Holder's licence. One respondent said that such terms "can be very confusing and make the process more difficult when you have to tailor the system for each item". Sometimes the terms may be as simple as a particular wording to go on the copied texts, or a time limit on the usage of the material. For other clearances, particularly the re-publication of audio-visual materials, the terms may be more complex to implement. However, even the simple terms and conditions become hard to manage when they are scaled up. The mean number of items cleared per annum by respondents was over 400 . Potentially then, there are over 400 different sets of wording, time limitations, security measures, etc, to deal with.

Another common complaint about licence terms was that they were ambiguous. One respondent commented that "Licence agreements need to be written in plain English and crystal clear - a lot of [the JISCmail list] Lis-Copyseek is about how to interpret ambiguity.” 
Of course one of the most important terms of permission is the price.

\section{Permission fees granted for no charge}

Not all permissions had a cost attached. Thirty-seven respondents indicated the percentage of their permissions that were granted for no charge. The responses can be seen in Figure 15.

\section{Figure 15}

The largest group of respondents (54\%) indicated that less than $10 \%$ of their permissions were granted for no charge. Six respondents (16\%) stated that between $31-50 \%$ of their permissions were granted for no charge. There was another peak of three respondents in the $71-80 \%$ range, and, interestingly, four in the $91-100 \%$ range. Although this latter category contained two respondents that didn't pay for their permissions (either by only copying material that was fee-free or by arrangement), that left two others that seemed to be quite successful permission-seekers!

Two respondents made interesting annotations to their response to this question. One wrote that CLARCS requests were never free, but that $46 \%$ of their direct requests were. Another commented that $55 \%$ of Short Loan requests were granted without charge, but only $7 \%$ of coursepack requests. Some respondents also found fees to be negotiable. On rejecting a permission on cost grounds, one respondent had the fee reduced by the publisher to an acceptable level.

\section{Average fees}

It was difficult to conclude upon an "average" permission fee. Although many respondents cited what they considered to be an average fee, very few actually indicated what the fees were for. There were three "average coursepack" quotes that ranged from $£ 350$, through $£ 650$, up to $£ 1,000$. There were eleven smaller quotes ranging from 70 pence to $£ 66.34$ which may well have been for individual items within coursepacks or items for Short Loan Collections, as these were the most frequently cited services requiring clearance. Three respondents cited a five or six pence per page per student charge which again must have been for coursepack or electronic short loan materials. CLARCS recommend a five pence per page per student to their rights holders for printed coursepacks. Information from HERON also confirmed that the vast majority of rightsholders charge five pence per page per student for digitising material. Another respondent noted that average fees vary widely between the types of rights holder approached. She wrote "the average per page fee being charged via the CLA is 5.5p. The average fee from publishers is 4.5p. The average fee from authors is 1.5p."

\section{Per page charges}

This does raise a question as to the logic of the per-page charge, and questions as to what clearers are actually paying for. For example, if clearers are paying to reproduce a unit of intellectual property, of what significance is the number of pages on which that intellectual property is printed? Why does it affect the price? The author has written an article that was parallel published in two journals - in one it was printed on four pages, in the other it was printed on five pages. If anyone wanted to reproduce it (and the author had assigned her copyright to the publisher, which she has not) they 
would pay more for one article than the other. This does seem to make a mockery of the per-page system. It appears to be an inappropriate transfer of per-page photocopying charges (which do make sense), to clearance fees.

\section{Other charging mechanisms}

The per-page charge is just one charging mechanism however. Six basic charging mechanisms were identified by respondents, although they went by many different names.

\section{Figure 16}

The most popular was the one-off fee, not limited by time or the amount copied. BLDSC copyright-cleared copies fall into this category. Fees could be limited by time in the form of annual fees or even a fee per semester, however a fee based on the number of pages or items copied and also limited by time was the second most common mechanism reported. This method is used for CLARCS fees where the number of pages in the item to be copied is multiplied by the number of students on the course. With the advent of electronic copying, fees per use - often referred to as royalty fees - also occured.

The significance of the range of charging mechanisms used is the impact they have on in-house clearance management systems. Such systems need not only to be able to cope with the different types of fees, but the different variations of that fee. For example, a fee limited by time might be for a semester, a year, two years, five years, and so on. Fees per use might be per print or per view. Charges for audiovisual materials become more complex still when taking territorial rights and options into consideration.

\section{Who pays?}

The final question regarding payment asked respondents "who pays the clearance fees? (i.e. library, departments, individuals)". There were 48 responses to this question.

\section{Figure 17}

Overall, departments were most frequently listed as those that pay the clearance fees. Fifty-two per cent of respondents said departments' alone foot the bills. Less than half this number, $23 \%$, said the library alone paid the clearance fees. In six cases the fees were split between the library and departments, and in three other cases with individuals as well.

To understand which services each category were paying for, data on the reasons for clearance were plotted against the above data. The analysis may be flawed in that the services specified as requiring clearance may not have all been accounted for when the question about who pays for them was put. However, it was thought this correlation may indicate some general trends. The graph below illustrates what services departments were paying for. 


\section{Figure 18}

It can be seen that coursepacks featured heavily in the analysis - 16 occurrences (64\%) in total. There were 9 occurrences of Short Loan, three of Distance Learning (DL) materials, and one of Electronic Short Loan.

The next graph illustrates what clearance fees libraries pay.

\section{Figure 19}

Short Loan Collection clearance fees - both print and electronic - feature quite heavily in this analysis. However three libraries indicated that they paid coursepack fees, and four paid fees for Distance Learning materials. Three respondents stated that their current payment arrangements (two paid for Distance Learning materials, and one for coursepacks), were only temporary and that in future they would look to charge the clearance fees back to internal customers.

The questionnaire data on who pays the copyright fees was borne out by the interview analysis. None of the copyright services paid the clearance fees themselves, they were all passed back to the relevant internal customers. Therefore, the decision as to whether to accept or reject a permission fee has to be made by that internal customer and not by the clearance service. This adds another layer of correspondence to the clearance process. All the services interviewed were centrally funded, so none charged their time back to internal customers either.

In most of the interviewees' experience, cleared coursepacks were given to students and the costs borne by the department. However the one interviewee's experience with selling coursepacks through the library bookshop resulted in losses as not all students bought them. These losses had to be borne by the department. The CLA have recently mentioned introducing a sale or return facility on coursepacks. This would dramatically change the economics of selling packs to students, reducing the risk of expensive clearance.

\section{Conclusions}

To say that rights clearance is a complex and time-consuming process is an understatement. Two-thirds of responding HEIs involved at least two members of staff on the task. On average an HEI submits over 400 clearance requests per year, one-third of which require chasing, five per cent of which are never answered at all. The clearance process itself is lengthy, requiring a minimum of ten distinct steps. There are up to fourteen different copyright licences to get to grips with, and there is clearly room for improvement with some clearing houses.

When asked for general comments on the clearance process, a great deal of frustration was evident in respondents' answers. One recommended action:

"the LIS [Library and Information Science] community needs to get its act together to influence all those involved (rights holders, publishers, governments) to improve the copyright situation especially in educational establishments. The process is unnecessarily complicated...Our students are 
losing out and cannot understand why an item can't go into the short loan when so much other information is freely available over the WWW."

Action, in the form of a series of recommendations to legislators, licensors and rights holders, was one of the outputs of this research. Also, assuming the copyright environment does not change, a list of "best practice" guidelines was written for copyright clearers. These are available in the full project report. One of the main difficulties with the UK clearance situation is that there are so many players and the problems could be addressed in different ways on many different levels. The LIS community needs to continue to publicise the problem of copyright clearance, in the hope that workable solutions will one day be found.

\section{References}

The ACORN Project, URL: http://acorn.lboro.ac.uk/

Digitisation news (2000) CLARION : the newsletter of the Copyright Licensing Agency, Winter 2000, 5.

Calvert, H.G. (2000) The impact of electronic journals and aggregate databases on interlibrary loan: a case study at Ball State University Libraries. New World Library, 101, (1153), 28-31

Commission of the European Communities (CEC). Amended proposal for a European Parliament and Council Directive on the harmonisation of certain aspects of copyright and related rights in the Information Society. CE COM(1999)0250

Copyright Licensing Agency. URL: http://www.cla.co.uk/

Gadd, Elizabeth (1997) Copyright Clearance for the Digital Library: a practical guide, Learned Publishing, 10, (3), 255-259

Guernsey, Lisa (2000) Books by the chapter or verse arrive on the internet this fall. New York Times on the web, July 18. URL: http://www.nytimes.com/library/tech/00/07/biztech/articles/18book.html

Higher Education Resources ON-demand (HERON), URL: http://www.heron.ac.uk/ Higher Education Statistics Agency (HESA), URL: http://www.hesa.ac.uk/

Weedon, Ralph (2000) Policy approaches to copyright in HEIs : a study for the JSC Committee for Awareness, Liaison and Training (JCALT). Glasgow: Centre for Educational Systems

Word count: 8, 274 